\title{
En búsqueda de visibilización: experiencias y necesidades de las mujeres excombatientes de las FARC-EP en el escenario de construcción de paz ${ }^{1}$
}

\section{Seeking visibility: experiences and needs of female ex-combatants of the FARC-EP on the stage of peacebuilding}

\author{
Angie Lorena Ruiz Herrera (iD) \\ Universidad Nacional de Colombia \\ alruizh@unal.edu.co
}

\section{Omar Huertas Diaz (iD)}

Universidad Nacional de Colombia

ohuertasd@unal.edu.co

\begin{abstract}
Resumen
La insurgencia se ha caracterizado por divulgar discursos de igualdad entre hombres y mujeres, vinculando a sus filas la participación de la mujer como combatiente. Teniendo en cuenta el amplio protagonismo de la mujer en la guerra, esta investigación se pregunta acerca de las experiencias, aprendizajes y retos de las mujeres excombatientes de la guerrilla de las FARC-EP; lo anterior, en razón de la reincorporación a la civilidad que han emprendido estas mujeres derivada de la firma del Acuerdo Final para la Terminación del Conflicto y la Construcción de una Paz Estable y Duradera. Para esto, se indaga acerca de aspectos como salud, trabajo y seguridad; además, se realiza una entrevista semiestructurada a profundidad a cinco mujeres excombatientes de las FARC-EP. Se halla que el contexto social de crianza caracterizado por el abandono estatal y la presencia constante de la guerrilla facilitó su ingreso a la organización; igualmente, se encuentra la resignificación del rol de la mujer, convirtiéndose en un sujeto político e incidente en el cambio social. Asimismo, se indaga sobre la maternidad y la crianza y se identifican mujeres decididas con el cambio social en pro de sus nuevas familias $y$ comprometidas con la lucha desde el escenario politico. Finalmente, se identifican retos relativos a la seguridad y temores relacionados con la terminación de los acuerdos pactados, que se constituyen como obstáculos para la reincorporación social efectiva de las mujeres excombatientes.
\end{abstract}

Palabras clave: mujer, mujer excombatiente, Acuerdo Final, FARC-EP, farianas, reincorporación social.

\begin{abstract}
The insurgency has been characterized by spreading discourses of equality between men and women, linking to its ranks the participation of women as combatants. Taking into account the broad role of women in war, this research asks about the experiences, learning and challenges of women ex-combatants of the FARC-EP guerrilla, the previous, because of the reintegration to civility that They have undertaken these women derived from the signing of the Acuerdo Final para la
\end{abstract}

1 Investigación desarrollada en el marco del proyecto Caracterización de la mujer madre excombatiente de las FARC-EP: Implicaciones de política pública con enfoque diferencial, de género y territorial; financiado por la convocatoria Jóvenes Investigadores e Innovadores por la Paz 2017, COLCIENCIAS - Universidad Nacional de Colombia. 
terminación del conflicto y la construcción de una paz estable y duradera. For the above, it inquires about aspects such as health, work, security and others in the ARN registers and, in addition, a semi-structured in-depth interview is conducted with five ex-combatant women of the FARC-EP, residents of the Territorial Space of Training and Reintegration of Icononzo Tolima and in the city of Bogotá. Finding that the social context of parenting characterized by state abandonment and the constant presence of the guerrillas, facilitated their entry into the organization; also, there is the resignification of the role of women, becoming a political subject and incident in social change. Likewise, it inquires about motherhood and upbringing, finding women determined with social change in favor of their new families and committed to the fight from the political scene. Finally, the identified challenges include security and fears with the termination of the agreed agreements, which are obstacles to the effective social reintegration of ex-combatant women.

Keywords: ex-combatant woman, Final Agreement, FARC-EP, farianas, social reintegration.

Artículo: Recibido el 29 de abril de 2019 y aprobado el 4 de julio de 2019.

\title{
Cómo citar este articulo:
}

Ruiz-Herrera, A. L., Díaz, OH. (2019). En búsqueda de visibilización: experiencias y necesidades de las mujeres excombatientes de las FARC-EP en el escenario de construcción de paz. Reflexión Política 21 (42), pp. 9-28. doi: $10.29375 / 01240781.3595$

\section{Introducción}

\begin{abstract}
El mito de 'sexo débil' se ha hecho trizas ante la realidad de una fémina que no ha vacilado en ocupar las trincheras de combate junto a los hombres, que no ha escatimado esfuerzos en cada una de las tareas acometidas por nuestro pueblo en el complejo camino de su desarrollo
\end{abstract}

Vilma Espin

El triunfo de la Revolución Cubana en los años 50 del siglo XX permitió la defensa de la consigna de la lucha armada en los países de la región; con ello, nacieron organizaciones guerrilleras en El Salvador, Nicaragua, Uruguay y Colombia, impulsadas por la lucha y reivindicación social (Huertas, Ruiz \& Botia, 2018). De manera paralela, el feminismo, desde sus diferentes vertientes, se posicionaba como una alternativa de combate para y de las mujeres que las arrancaba de sus roles tradicionales y las situaba en un escenario social y político diferente al escenario cotidiano del trabajo doméstico. Así, desde los años setenta del siglo XX las mujeres empiezan a posicionarse como representantes importantes dentro de los grupos guerrilleros (Jiménez, 2014), ejerciendo la libertad que por tanto tiempo se les había negado, siendo relegadas al hogar y a la vida privada. Con las guerrillas, las mujeres comienzan a concebirse como individuos sociales y políticos, "lo que conlleva un cambio en su propia identidad y un aumento de la concepción propia de su papel en la sociedad” (Jiménez, 2014, p. 386).

De esta manera, las guerrillas se convierten en el escenario de materialización de las consignas feministas, pues, a partir de su pertenencia, la lucha por los derechos trasciende de la defensa de los propios a la reclamación de los derechos sociales, lo que genera movimientos y documentos que reflejarían dicho logro, entre ellos se encuentran: Union of Palestinian Women la cual publica la Declaration of Principles on Palestinian Women's Rights; también la Unión Nacional de Mujeres Saharauis, organización vinculada al Frente POLISARIO, creada en 1974 por y para las mujeres del Sáhara Occidental (Jiménez, 2014).

Por su parte, Vanegas (2017) señala otros antecedentes en los cuales se evidencia la participación de las mujeres en las guerrillas del mundo. Por ejemplo, señala la etnia Ijaw de Nigeria la cual se levanta contra el ingreso de capitales extranjeros y la extracción de recursos naturales, luchas que cuentan con la participación activa de mujeres. Igualmente, en Asia se documenta la participación de las mujeres en 
las guerrillas musulmanas (Hezbollah, Hamas, en Palestina; Talibanes en Afganistán y Pakistán); en los grupos insurgentes de Tailandia y, en la India, las mujeres participaron de manera activa en la guerrilla maoísta del Ejército Guerrillero Popular de Liberación.

A nivel latinoamericano, Vilma Espín, líder de la Revolución Cubana junto con Fidel Castro y el Che Guevara, impulsó el nacimiento de grupos de guerrilleros, en los cuales, tanto en el nivel logístico como en el de combate, participaron las mujeres: el Movimiento de Liberación Nacional Tupamaros (MLN-T), que nació en 1966 en Uruguay; el Frente Farabundo Martí para la Liberación Nacional Frente Democrático Revolucionario (FMLN-FDR) en El Salvador; y el Frente Sandinista de Liberación Nacional (FSLN) en Nicaragua. Frente al caso específico de El Salvador, se documenta que, entre 1981 y 1992, el grupo se constituía por un $60 \%$ de mujeres en el área logística y un 30 \% en el área militar. En Nicaragua, se afirma que "la numerosa participación de la mujer en el proceso revolucionario fue en parte un resultado de su integración en la economía nacional” (Stanford, s.f., párr. 2), lo anterior, debido a su amplia participación en el sector laboral.

Por su parte, los orígenes del conflicto armado en Colombia se remontan a los años 50 del siglo XX, como resultado de la constitución de la violencia como elemento transversal en la lucha del poder político por parte de los partidos tradicionales de la época (Partido Conservador vs. Partido Liberal). Dicha práctica vería su punto álgido en el periodo histórico denominado como La Violencia, resultado del magnicidio de Jorge Eliécer Gaitán, transcurrido entre los años 1946 y 1958.

El periodo de La Violencia en Colombia fue caracterizado por una ola de intimidación contra diferentes movimientos agrarios, campesinos, obreros y populares que se aglutinaron alrededor de las ideas gaitanistas; no obstante, la agudización de esta violencia se presenta con la muerte de Jorge Eliécer Gaitán, en el hecho histórico conocido como El Bogotazo. A partir de este momento, se conforman o se hacen evidentes las agrupaciones armadas al servicio de cada uno de los partidos políticos; por un lado, se encuentra la Policía Chulavita y Los Pájaros al servicio del Partido Conservador y, por el otro, las guerrillas liberales y las autodefensas campesinas, ligadas al Partido Liberal (GMH, 2013). Según Paul Oquist, citado por Grupo de Memoria Histórica (GMH, 2013):
Entre 1948 y 1966, 193.017 personas resultaron muertas producto de la violencia partidista en Colombia. La mayor proporción tuvo lugar entre 1948 y 1953, los años de mayor intensidad de violencia, según los estudiosos del tema. Los departamentos más afectados por los homicidios fueron el Antiguo Caldas (24,6 \%), Tolima (17,2 \%), Antioquia (14,5\%), Norte de Santander (11,6\%), Santander (10,7 \%) y Valle del Cauca (7,3 \%). En cuanto al abandono o despojo de tierras, Oquist calculó que los propietarios de tierras perdieron 393.648 parcelas, y que los departamentos más afectados fueron Valle del Cauca, Tolima, Cundinamarca, Norte de Santander y Antiguo Caldas (p. 115)

Teniendo en cuenta la magnitud de estos hechos, se produce un periodo de transición, en el cual asciende a la presidencia Gustavo Rojas Pinilla, quien ofrece amnistías a las guerrillas liberales y autodefensas campesinas. Las primeras se acogen a la propuesta de Rojas Pinilla, mientras las segundas la rechazan. Este rechazo produjo una ofensiva desde la presidencia contra estos movimientos, la cual fue utilizada como argumento para el agrupamiento y justificación de la continuación de la lucha armada. La ofensiva contra estos movimientos continúa durante el periodo denominado como Frente Nacional, durante el cual se perpetran diferentes operaciones militares contra territorios llamados Repúblicas Independientes. Estos territorios fueron denunciados de esta forma por el senador Álvaro Gómez Hurtado, quien los definía como "zonas campesinas en armas que escapaban al control estatal" (GMH, 2013, p. 121). En este contexto, se adelantóla operación contra Marquetalia en mayo de 1964, hecho que permite el tránsito de las autodefensas campesinas a movimientos guerrilleros autodenominados. Con esto, entran al escenario sociopolítico del país movimientos guerrilleros como las FARC-EP, UCELN, EPL, Quintín Lame, M-19, entre otros.

De manera específica, Eduardo Pizarro (1991) señala que las FARC-EP surgen luego de tres fases diferenciadas: la primera, resultado de la resistencia armada como autodefensa campesina en el marco de la existencia del Partido Comunista Colombiano (PPC); la segunda, producto de la conversión de los núcleos campesinos en guerrilleros; y la tercera derivada de la conformación de las denominadas Repúblicas Independientes y los planes de seguridad apoyados por el gobierno norteamericano. 
Estas fases, le permitieron posicionarse como un grupo armado fuerte y con necesidad de mantener apoyo en diferentes regiones y zonas estratégicas, por lo cual, la vinculación de la mujer, aparte de los deseos mismos de emancipación dentro de la lucha armada por la misma, se sitúan en

Los cambios en la naturaleza política de la lucha guerrillera, la percepción del peligro que implicaba perder el apoyo de las mujeres en caso de que se involucrasen en los partidos tradicionalistas y la difusión del pensamiento feminista, encauzado de manera que favoreciera los intereses de la izquierda en la lucha proletaria. (Ibarra, 2008, p. 73)

Esto se materializa según Gutiérrez \& Carranza (2017) en la séptima conferencia de las FARC, en la cual se definen como "Ejército del Pueblo", evidenciando la necesidad ya manifestada y acogiendo como estrategia la autorización de mujeres como combatientes. De esta manera, se ponía en marcha la trasformación de la estructura, siendo capaz de posicionarse como un ejército capacitado y con cobertura amplia en el territorio. Asimismo, mencionan que el reclutamiento de mujeres se presenta como estrategia de fortalecimiento de la organización, se reconoce también el empuje de la mujer que desde labores tradicionales demostró ser capaz de involucrarse en la organización como guerrillera (Gutiérrez \& Carranza, 2017). Esto permite reconocer el grado de agencia de la mujer combatiente en su lucha por el reconocimiento, desvirtuando la noción victimizante tradicional que se le ha adjudicado. Así, el involucramiento de las mujeres como combatientes tiene dos consecuencias: por un lado, permite que la estructura guerrillera se fortalezca y, por otro, promueve su re significación, trasfigurando su rol doméstico, privado y familiar, a un rol activo, político y social (Gutiérrez \& Carranza, 2017).
Surge un nuevo espacio, donde la libertad de elegir era permitido y en el cual sus deberes como mujer ya no estaban reducidos al matrimonio y la familia (Jiménez, 2014).

La magnitud de la participación de las mujeres en la insurgencia colombiana se refleja en los altos porcentajes registrados. Según Elson (2016) alrededor del $30 \%$ de los combatientes del M-19 eran mujeres, situación presentada también en las FARC-EP, donde, además, se documenta que hasta el $40 \%$ de la comandancia de nivel medio estaba a cargo de las mujeres. Asimismo, en los procesos de paz de la década de los noventa, se registraron 1.183 desmovilizadas, lo cual equivale al $24 \%$ del total de desmovilizados. En las negociaciones con las Autodefensas Unidas de Colombia se desmovilizaron de manera colectiva 1.911 mujeres $\mathrm{y}$, de manera individual, 5.450 mujeres tanto de grupos de autodefensas como de guerrillas. Es decir, que desde 1990 hasta 2014 se desmovilizaron 8.554 mujeres de los grupos armados ilegales de Colombia (OPC, 2015; 2016).

Por su parte, en el mes de agosto de 2018, la Agencia para la Reincorporación y la Normalización (ARN) reporta el número de mujeres tanto en proceso de reintegración, como aquellas que han culminado el proceso. Estas cifras se presentan en la tabla 1 .

Como se evidencia, han sido miles las mujeres que han participado en los diferentes grupos armados en Colombia. Esto plantea la necesidad de crear estrategias que permitan su reintegración efectiva a la sociedad civil y que el empoderamiento aprendido mediante su tránsito en la organización se conserve y replique en pro de la garantía de los derechos de las mujeres.

Dados estos antecedentes, la investigación se pregunta ¿cómo son estas mujeres?, ¿qué necesidades tienen en este escenario de construcción

Tabla 1

Número de hombres y mujeres en los momentos de la reintegración

\begin{tabular}{llllll}
\hline $\begin{array}{l}\text { Momento de la } \\
\text { reintegración }\end{array}$ & Mujeres & \% & Hombres & \% & Total \\
\hline Ingresó & 6.942 & 13,431363 & 44.743 & 86,568637 & 51.685 \\
\hline En proceso & 1.877 & 21,016683 & 7.054 & 78,983317 & 8.931 \\
\hline Culminó & 3.756 & 16,990094 & 18.351 & 83,009906 & 22.107 \\
\hline Total & 12.575 & 15,201335 & 70.148 & 84,798665 & 82.723 \\
\hline
\end{tabular}

Fuente: Agencia de para la Reincorporación y la Normalización (2018). 
de paz?, ¿cuáles son sus principales retos? Por esta razón, se presentan a lo largo del texto los testimonios y significados de cinco mujeres excombatientes de las FARC-EP referentes a su experiencia en la organización, a los aprendizajes y reconstrucción de su rol como mujer y a las oportunidades y retos que se les presentan como excombatientes en el escenario de paz actual. Asimismo, con el fin de dar respuesta a la identificación de necesidades, se presentan datos institucionales que dan cuenta de condiciones de salud, trabajo y seguridad; aspectos claves para la reincorporación de estas mujeres en el escenario actual.

\section{Metodologia}

La investigación sigue una metodología mixta, pues, inicialmente, sepresentanlosresultadoscuantitativos de la información descriptiva proporcionada por la Agencia para la Reincorporación y la Normalización $(\mathrm{ARN})$, datos que permiten aproximarse de manera general a la situación de las mujeres excombatientes, particularizando aspectos como pareja, seguridad, acceso a la salud y al empleo.

Por otro lado, se encuentra la perspectiva cualitativa que se apoya en el paradigma de la teoría fundada, esto en la medida que pretende derivar proposiciones -más que teorías- de las historias de vida de las mujeres entrevistadas (Álvarez \& Jurgenson, 2003). Las participantes de la investigación fueron 5 mujeres excombatientes de las FARC-EP, 4 de ellas residentes en el Espacio Territorial Antonio Nariño de Icononzo (departamento del Tolima) y una excombatiente residente en la ciudad de Bogotá. En la tabla 2 se presentan los datos sociodemográficos de las participantes.

Para la recolección de la información cuantitativa se recurre a datos institucionales de la ARN, quienes proporcionan la información en bruto para el corte de agosto de 2018. Para la recolección de la información cualitativa se genera una entrevista semiestructurada a profundidad, la cual se aplica tras la presentación del consentimiento informado, abordando las siguientes temáticas generales:

- Características generales: sexo, edad, pertenencia étnica, situación de discapacidad, ciudad de nacimiento, educación, entre otros.

- Historia de vida, vinculación al grupo armado y familia: nacimiento y crecimiento, relaciones familiares, edad de ingreso al grupo armado, motivaciones de ingreso al grupo, afectación de las relaciones familiares, permanencia en la organización, sentimientos actuales referentes a su familia, relaciones de pareja o sentimentales, entre otros.

- Pertenencia a la organización siendo mujer: discriminación dentro del grupo armado, sexualidad, maternidad, relaciones sociales,

Tabla 2

Información sociodemográfica

\begin{tabular}{|c|c|c|c|c|c|c|c|}
\hline Participante & $\begin{array}{l}\text { Edad } \\
\text { (años) }\end{array}$ & $\begin{array}{l}\text { Edad } \\
\text { vinculación } \\
\text { (años) }\end{array}$ & $\begin{array}{l}\text { Tiempo } \\
\text { organización } \\
\text { (años) }\end{array}$ & Hijos & Educación & Nacimiento & $\begin{array}{l}\text { Rango más } \\
\text { alto alcanzado }\end{array}$ \\
\hline 1 & 44 & 16 & 27 & 1 & Bachiller & Boyacá & No refiere \\
\hline 2 & 33 & 13 & 20 & 3 & $\begin{array}{l}\text { Primaria } \\
\text { incompleta }\end{array}$ & Meta & $\begin{array}{l}\text { Comandante } \\
\text { de escuadra }\end{array}$ \\
\hline 3 & 32 & 11 & 20 & 1 & $\begin{array}{l}\text { Primaria } \\
\text { completa }\end{array}$ & Meta & $\begin{array}{l}\text { Comandante } \\
\text { de escuadra }\end{array}$ \\
\hline 4 & 30 & 12 & 16 & 1 & $\begin{array}{l}\text { Primaria } \\
\text { incompleta }\end{array}$ & Meta & $\begin{array}{l}\text { Comandante } \\
\text { de escuadra }\end{array}$ \\
\hline 5 & 26 & 14 & 13 & 2 & $\begin{array}{l}\text { Primaria } \\
\text { completa }\end{array}$ & Caldas & Secretaria \\
\hline Media & 33 & 13,2 & 19,2 & - & - & - & - \\
\hline $\begin{array}{l}\text { Desviación } \\
\text { estándar }\end{array}$ & 6,70 & 1,92 & 5,26 & - & - & - & - \\
\hline
\end{tabular}

Fuente: elaboración propia. 
actividades dentro de la organización, rango ocupado, oportunidades, sentimientos, entre otros.

- Comunidad y aceptación como mujer excombatiente: relaciones con las comunidades, discriminación, exclusión, igualdad de oportunidades en el proceso de reinserción, entre otros.

- Trabajo, educación y salud: satisfacción de necesidades básicas, empleabilidad, oportunidades de educación, afiliación o atención en salud, acceso a servicios para menores de edad, entre otros.

- Seguridad y proceso de paz: percepción de seguridad, amenazas, estrategias de protección, riesgo de reincidencia.

El procedimiento seguido en esta investigación comienza con la búsqueda de la población excombatiente y, posteriormente, con la visita a la zona territorial Antonio Nariño de Icononzo (Tolima). Asimismo, se contactó en la ciudad de Bogotá a una mujer excombatiente de las FARC$\mathrm{EP}$, pospenada, quien colaboró ampliamente con esta investigación. Con ello, se aplica la entrevista a profundidad, mediante la cual las mujeres excombatientes relatan sus historias de vida, su vida en la organización y su perspectiva futura.

\section{Resultados}

\section{Caracterización a partir de información institucional}

Inicialmente, se presentan los resultados cuantitativos de la investigación, derivados del análisis descriptivo de los datos suministrados por la ARN. De esta manera, para agosto de 2018 se registran 60.155 excombatientes entre hombres y mujeres; con respecto a la población de las FARCEP, en particular, se presentan 19.539 personas (15.435 hombres y 4.104 mujeres). Las edades de los excombatientes registrados en la ARN se presentan en la figura 1, en donde se evidencian frecuencias altas en el rango de edad de 26 a 40 años.

En relación con la configuración familiar de los excombatientes, las figuras 2 y 3 reflejan el número de personas con cónyuge y con hijos.

Así, se encuentra que un número importante de mujeres que ingresan a los procesos de reintegración en la Agencia tienen cónyuge. Esta situación que se repite al analizar la variable "si tiene hijos", en donde se registran 2.124 mujeres con hijos en estado de ingreso, 1.135 en proceso y 1.135 mujeres que han culminado y tienen hijos. Esta situación se evidencia, principalmente, en los Espacios Territoriales de Capacitación y Reincorporación (ETCR), en donde crecen cientos de niños hijos de excombatientes de las FARC-EP, a quienes se les deberá garantizar sus derechos

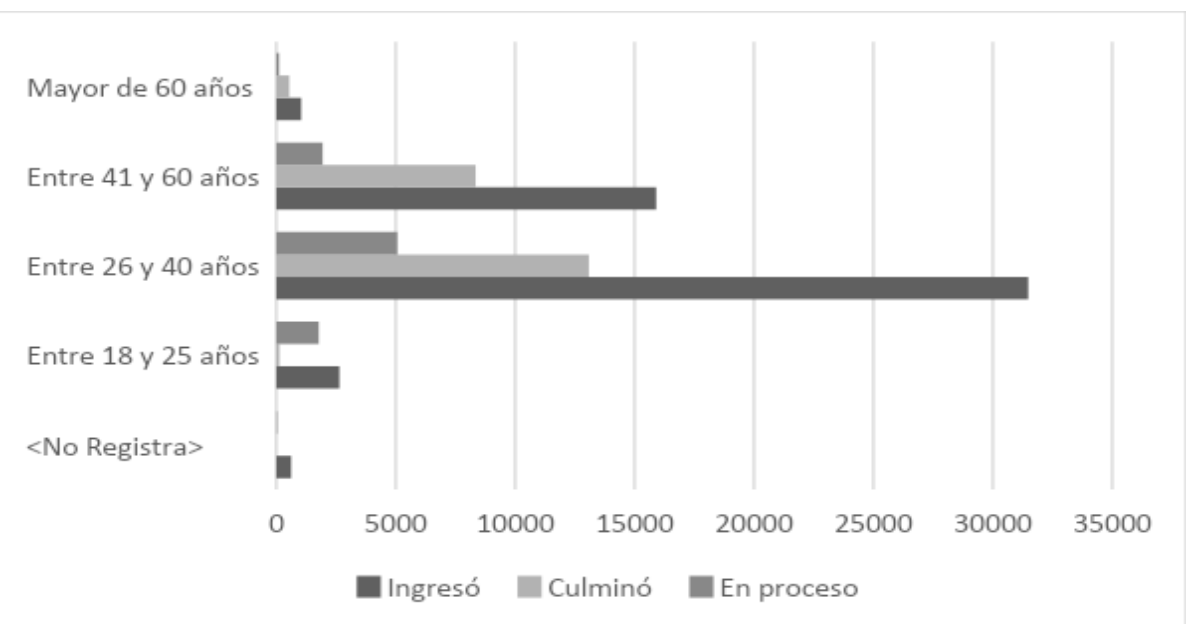

Figura 1. Edades de la población excombatiente según la ARN.

Fuente: elaboración propia a partir de ARN (2018). 


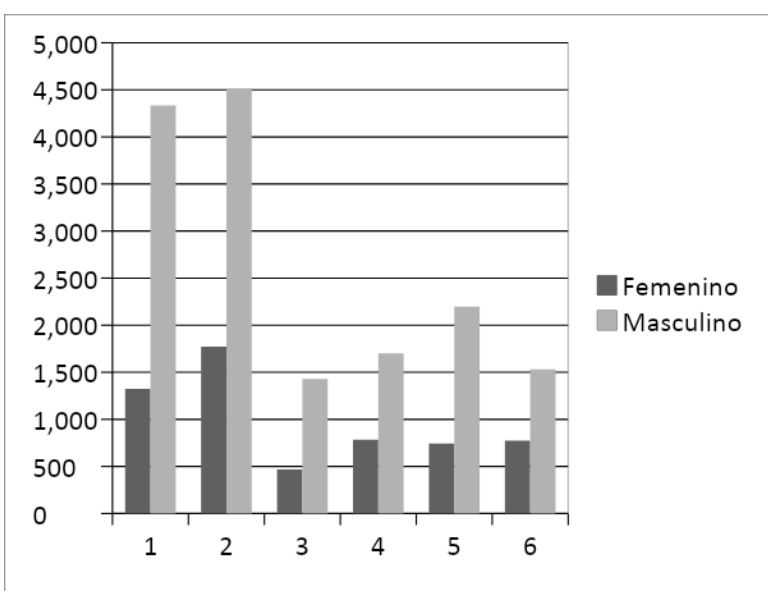

Figura 2. Personas con cónyuge según género y momento del proceso

Fuente: elaboración propia a partir de ARN (2018).

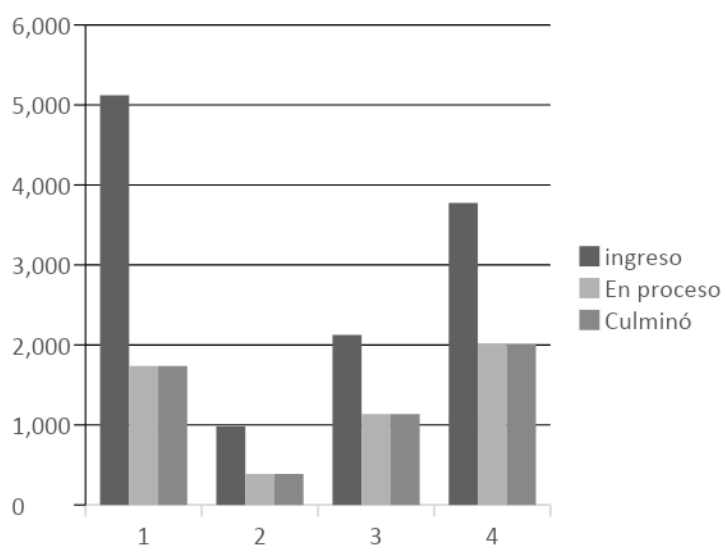

Figura 3. Personas con hijos según sexo y momento del proceso

Fuente: elaboración propia a partir de ARN (2018).

humanos y fundamentales. Al respecto, la Defensoría del Pueblo (2017) encuentra vulneración de derechos de los niños, niñas y adolescentes (NNA) que viven en los ETCR, pues no existen suficientes espacios educativos para su formación (deben acudir a centros educativos rurales en donde son estigmatizados como guerrilleros); adicionalmente, se reconoce que no todos los NNA de los ETCR están recibiendo educación formal; finalmente, la Defensoría encuentra que el Instituto Nacional de Bienestar Familiar no precisa información frente a la reparación administrativa de los menores en el marco de la Ley 1448 de 2011.

En lo relacionado con el acceso a la salud en Colombia, la Ley 100 de 1993 establece dos regímenes de acceso al servicio de salud: contributivo y subsidiado. El primero es resultado de los aportes de los trabajadores al sistema y el segundo responde a la responsabilidad del Estado de garantizar el acceso a la salud a toda la población colombiana: siendo la salud un derecho conexo a los derechos fundamentales, es imprescindible la garantía del mismo. En la figura 4 se presenta el número de excombatientes de las FARC-EP en los regímenes contributivo y subsidiado, asimismo, se registra el número de personas no afiliadas.

La ocupación o situación laboral es una de las variables más relevantes para la reintegración económica de los y las excombatientes. Esto garantizará su permanencia en la legalidad y la configuración de un nuevo proyecto de vida (ver figura 5).

Finalmente, se presentan los resultados descriptivos en materia de seguridad, en estos se registra el número de homicidios a excombatientes, casos de riesgo y reincidencia probada. Frente a los casos de homicidio se cuenta con registros de la población que ingresa al proceso en la ARN: se encuentran, para el periodo registrado, 25 homicidios de mujeres y 602 de hombres. Los casos de riesgo se definen como las situaciones delictivas que ponen en riesgo la integridad del excombatiente, situaciones que se presentan en la tabla 3.

Como se evidencia, la principal modalidad de riesgo para los dos sexos es la amenaza, seguida de atentados y persecuciones. Esta situación no solamente pone en riesgo la vida de los excombatientes involucrados, sino que, además, impulsa o incentiva la revinculación a grupos ilegales, en busca de protección para sí mismos y sus familias. 


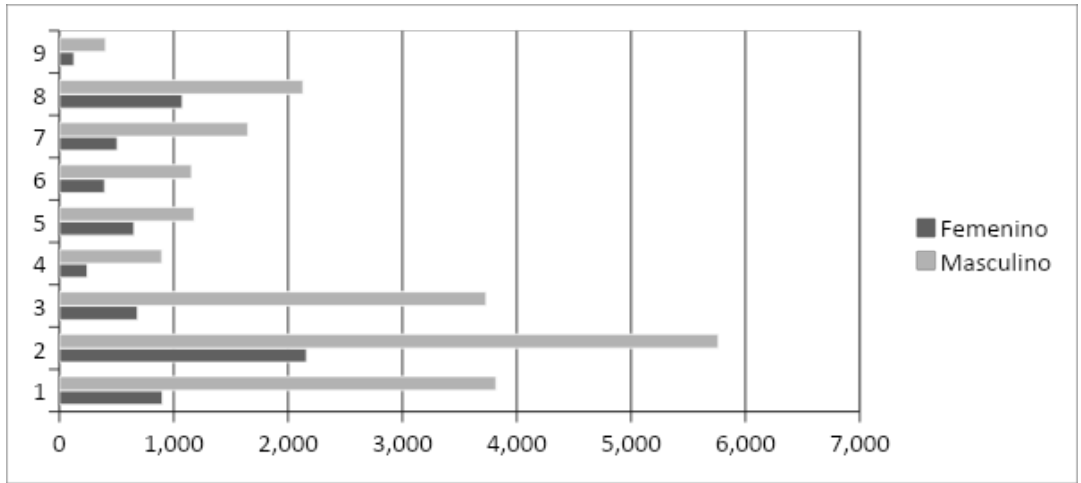

Figura 4. Acceso a la salud de los excombatientes

Fuente: elaboración propia a partir de ARN (2018).

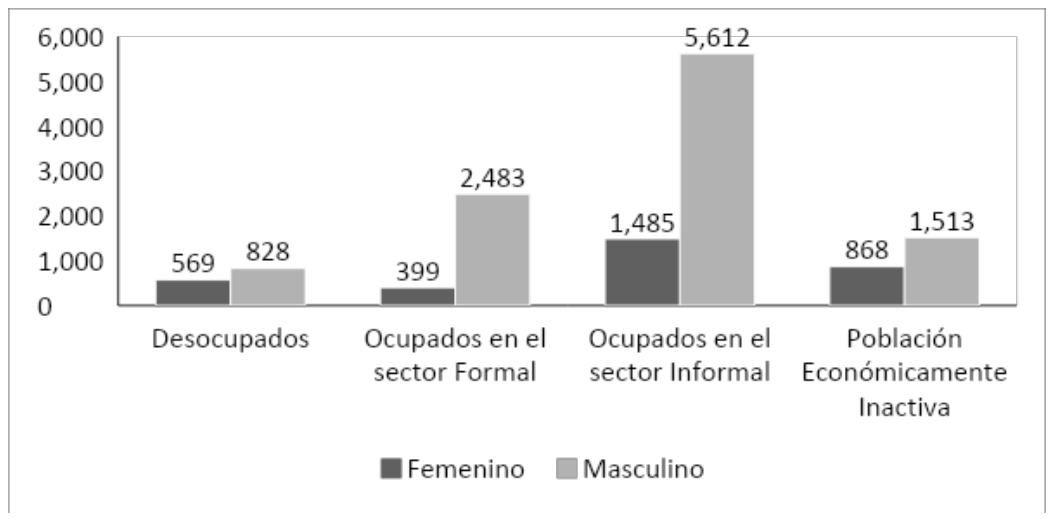

Figura 5. Situación laboral de excombatientes y momento del proceso

Fuente: elaboración propia a partir de ARN (2018).

Tabla 3

Número de situaciones de riesgo para excombatientes en los procesos de la ARN (2018) desagregados por sexo

\begin{tabular}{lllllll}
\hline $\begin{array}{l}\text { Riesgo / momento del } \\
\text { proceso de reintegración }\end{array}$ & Ingresó & & En proceso & \multicolumn{2}{c}{ Culminó } \\
\hline Sexo & Hombre & Mujer & Hombre & Mujer & Hombre & Mujer \\
\hline Amenaza & 1.405 & 335 & 448 & 128 & 427 & 152 \\
\hline Atentado & 108 & 8 & 52 & 4 & 17 & 2 \\
\hline Desplazamiento forzado & 20 & 6 & 13 & 5 & 1 & 1 \\
\hline Extorsión & 1 & 1 & 1 & 1 & 1 & No registra \\
\hline Persecución & 140 & 26 & 61 & 12 & No registra \\
\hline Otro & 2 & 1 & 2 & 0 & 39 & 12
\end{tabular}

Fuente: elaboración propia a partir de ARN (2018).

\section{Las voces de las mujeres excombatientes: retos, posibilidades y sueños}

De las entrevistas realizadas con las mujeres excombatientes se derivan las categorías y subcategorias que se presentan en la figura 6 .

\section{Infancia y familia}

En esta categoría se agrupan las respuestas de las mujeres entrevistadas relacionadas con su vida antes de la vinculación al grupo armado, específicamente, menciones relacionadas con su familia y su infancia, puesto que, como se mostró anteriormente, las mujeres entrevistadas ingresaron 


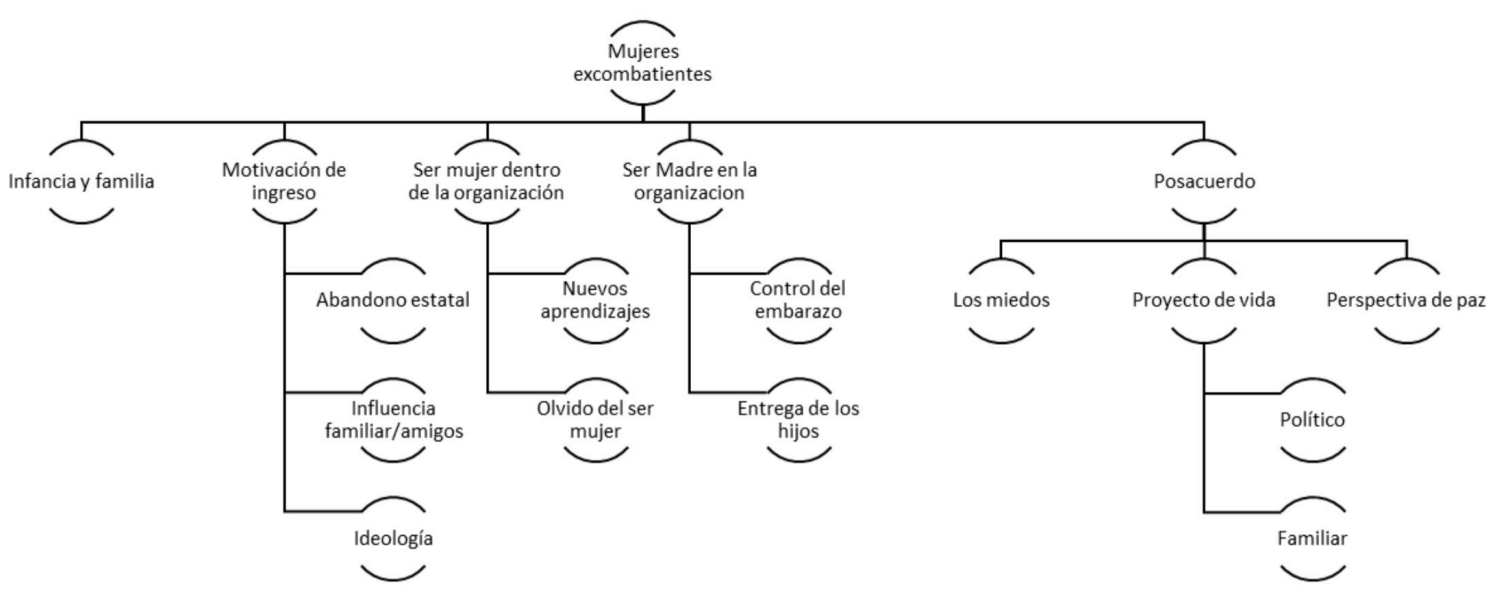

Figura 6. Categorías derivadas del trabajo cualitativo

Fuente: elaboración propia.

al grupo armado siendo menores de edad. Al respecto, Valencia \& Daza (2010) documentan infancias de las mujeres excombatientes en la marginalidad, la pobreza y el maltrato, lo cual las impulsa a su vinculación al grupo armado. Asimismo, Lesmes (2016), en el diálogo con mujeres excombatientes, encuentra diferentes experiencias de infancia y familia: así, por un lado, se relatan testimonios en donde el maltrato y la ausencia de los padres es un punto problemático y, por el otro, se resaltan familias tradicionales, en las cuales el hombre cumple el rol de proveedor y la madre de cuidadora. Adicionalmente, las condiciones de pobreza y falta de oportunidades de las regiones en las cuales habitaban fue un factor que se resaltó en la investigación de Lesmes (2016).

Los relatos de las excombatientes con las cuales se tuvo la oportunidad de dialogar no distan de lo encontrado por otras autoras, como las documentadas anteriormente. De esta manera, las mujeres entrevistadas señalan su crecimiento en zonas rurales, en ambientes familiares tradicionales $y$, en algunas ocasiones, con la falta de alguna de las figuras de apoyo:

P2: yo me crié en el campo, mi relación siempre fue con mi mamá y con mis hermanos, porque pues mi papá muy joven o sea él nos dejó, se separaron por problemas de trago, mi papá tomaba mucho y mi mamá se fue al campo y nos llevó, yo ahí terminé los estudios en el campo, y pues no, normal, mi juventud y mi niñez pues me la pase en el estudio; $y$ los fines de semana me iba para la finca, donde mi mamá trabajaba.
Asimismo, con respecto las motivaciones de ingreso, una de las participantes señala que crece en una familia comunista, siendo esta la influencia más fuerte para el ingreso al grupo armado. Sin embargo, el pertenecer a una familia con dicha postura trajo como consecuencia la pérdida de familiares y una infancia y adolescencia caracterizadas por la persecución. Lo anterior en razón del genocidio político sucedido en Colombia contra la Unión Patriótica (UP), grupo político surgido luego de las negociaciones del expresidente Belisario Betancur y las FARC, cuyo genocidio derivó en el rompimiento de las negociaciones y la continuación de la lucha armada. Al respecto, extractos del testimonio de esta sobreviviente de la UP:

P5: digamos que yo tuve la fortuna de haber nacido y haberme criado en una familia comunista, mi motivación fue más política, no por rencores, venganza, no, por convicción, pues mi militancia comenzó muy chinchesita (...) milité en la célula de partido, en la UP, entonces cuando ingresé a las FARC ingresé por convicción.

En el 91 asesinaron a mi papá y a mis dos hermanas mayores porque éramos militantes de la Unión Patriótica, estuvimos una temporada más o menos del 85 al 90 aquí en Bogotá, cuando comenzó el genocidio de la UP, somos sobrevivientes de ese genocidio y decidimos regresar al pueblo y seguimos con la militancia y estando en Aquitania el ejército asesina a mi papá y a mis dos hermanos mayores.

Por otro lado, la concepción de familia se transforma en la organización, creando nuevos 
lazos que aún hoy se conservan, lazos que en la actual implementación de los acuerdos de paz se transforman para crear alianzas de paz, para luchar políticamente y en contra de la exclusión. Estos dos relatos son ejemplo de lo anterior:

P5: mi apoyo social así grande aparte de mi mamá, mi núcleo familiar, son todos esos guerrilleros $y$ ex guerrilleras de base que conoci durante todos esos recorridos que son mi gran familia, que hemos procurado fortalecer esos lazos de familiaridad (...) estar pendientes unos de los otros (...) la gran familia fariana siempre será la familia fariana.

P3: la unión; uno al compartir, al relacionarse con gente que usted nunca ha distinguido y que con el tiempo ya hace parte de su familia, como si fueran hermanos ya tanto tiempo compartiendo y pues llega un guerrillero que no haya estado andando con usted, es como si ya lo hubiera distinguido ya hace mucho tiempo; entonces como si fuera un hermano más, como, o sea, la confianza y se familiariza uno con la gente.

Las concepciones de la infancia y la familia trascienden del escenario de crecimiento, la familia se reconfigura y se amplía: ahora no solo el núcleo tradicional es concebido como familia, sino también aquellos que se conocen en el recorrido de lucha. Igualmente, y a pesar de las circunstancias se recuerdan sin rencores la infancia y la familia que brindó la primera socialización al infante.

\section{Motivación de ingreso}

Fueron diversas las respuestas relacionadas con la motivación de ingreso a la organización. Se encontraron motivaciones ligadas al abandono del Estado vs. la presencia constante del grupo armado en la región, la influencia de amigos y/o familiares y la confianza en la ideología promulgada por el grupo armado.

Así, algunas de ellas manifestaron que dicho abandono estatal se tradujo en la cercanía de la guerrilla con sus comunidades. Esto les permitió conocer las dinámicas e ideas de esta, para así tomar la decisión de ingresar en la estructura armada:

P1: se encontraba uno a la guerrilla en la población. $Y$ pues uno de mirar tanto, asi se hace amigos. Yo me hice amiga de un amigo de una amiga y ellos fueron quienes me convidaron, me gustó y me fui.
P2: como me crié en zona guerrillera, pues, me crié en ese ambiente entonces... me fui.

P3: pues yo vivía por allá en una vereda que se llama la 26, es una vereda humilde, estudiábamos; mi familia es humilde y pues por eso ingresé a la guerrilla; yo desde muy niña miraba guerrilla pero yo no sabía que eso era guerrilla; cuando cumpli como los 9 años empecé a entender que era guerrilla, pero no sabía cómo se organizaban ni nada y pues ya empecé a tener amigos de la vereda que invitaron, entonces ya empecé yo a la escuela: ya iban a la escuela a orientarnos y a todo eso.

Como se lee, la presencia de la guerrilla en las comunidades y el contacto con conocidos de esta, influyeron en la decisión de ingreso. Ante esto, es posible reflexionar acerca del papel del Estado en estos territorios, ya que algunas de estas mujeres conocen a la guerrilla como aquel regulador de las dinámicas territoriales ante la ausencia del Estado y la existencia de dinámicas territoriales asociadas al narcotráfico. Así, tal como lo menciona el Centro Nacional de Memoria Histórica (2014):

La intervención de la guerrilla se facilitó, además, porque dichas regiones eran zonas marginales, con poca presencia estatal, y en donde hacian falta obras de infraestructura y servicios públicos; asimismo, eranzonas que padecían crisis periódicas causadas casi siempre por la superproducción de la hoja de coca. En ese contexto, el orden que configuró la guerrilla se caracterizaba, entre otros, por garantizar la seguridad de los habitantes, al respaldar las transacciones comerciales de la hoja y regular los precios (p. 156).

Igualmente, la influencia familiar, ya sea porque existian miembros de la familia activos en la organización o por los conflictos dentro de la misma, se constituyeron como parte importante en la decisión de ingreso:

P2: mis hermanos ya eran guerrilleros, si se fueron mis hermanos, yo también puedo y siendo la única mujer de la casa.

P3: me gustó la guerrilla y aparte tenía unos hermanos en la guerrilla y mi familia era campesina, éramos de bajos recursos.

P1: dos de mis hermanas ingresaron primero que yo a las FARC. 
P3: pero yo ya había amenazado a mi papá porque un día me pegó muy duro, entonces yo le dije que, si me seguía pegando, entonces yo me iba para la guerrilla y pues más duro me dio, y me dijo que si me fuera, me fuera por algo que en verdad valiera la pena.

Por otro lado, fueron los ideales de la organización los que impulsaron a las mujeres a ingresar, pues -en concordancia con la reflexión sobre la ausencia estatal- estas mujeres evidenciaban las carencias y necesidades de sus poblaciones, encontrando en el discurso guerrillero la plataforma de lucha para el cambio de esta situación manifestada. $\mathrm{Al}$ respecto, algunos testimonios:

P1: y yo, siempre que iba a la población, me acordaba que el pueblo, que tal, que necesitaban muchas cosas, que uno ayudarlos, que ¿cuándo se daría ese día de la paz y del cambio?, ¿cuándo? Uno miraba todo eso.

P1: es de mirar uno que luchaban y luchaban por una paz, un cambio social y pues a mi también me gustó y yo dije pues yo también voy a ir a luchar, que si me metian y me fui a luchar.

Existen algunos factores comunes en los testimonios de las mujeres excombatientes y se relacionan con la cercanía a la comunidad de la guerrilla. Las mujeres excombatientes crecen con la guerrilla, configurándose esto como un plan de vida ante la evidencia de la aceptación por parte de sus familias (la mayoría menciona que antes de su vinculación ya existía algún familiar vinculado a la organización).

Otros autores también han encontrado estas y otras motivaciones. Así, Barrara (2018), luego de la revisión documental de estudios relativos a las motivaciones de ingreso de las mujeres al combate insurgente, enlista las siguientes: 1) gusto por la vida militar 2) situación anterior de violencia intrafamiliar 3) desempleo y pobreza 4) deseo de venganza o resentimientos personales 5) reclutamiento forzado 6) militancia en otros grupos políticos o sociales 7) el tener un compañero dentro de la organización 8) el querer desafiar la autoridad masculina (ya sea de padres o hermanos, en el marco de un orden familiar tradicional) (p. 27).

\section{Ser mujer dentro de la estructura armada}

Amplia bibliografía se encuentra acerca de la vivencia de la mujer en las filas guerrilleras.
Algunos sostienen que las mujeres militantes lo son por reclutamiento forzado y que sufren cientos de vejámenes dentro de la organización (Galvis, 2009; Navas \& Penagos, s.f.); otros señalan que es el grupo insurgente el que las empodera y las convierte en sujetos políticos (Ibarra, 2008).

En esta investigación se encuentra que las mujeres excombatientes resaltan en sus diferentes testimonios las condiciones de igualdad en la guerrilla. De esta manera, rescatan aprendizajes derivados a partir de ese trato igualitario, así como la desestructuración de ideales asociados a los roles, tales como el cuidado del hogar; por el contrario, dentro de la organización aprenden que como mujeres son libres de tomar sus decisiones. Sin embargo, existen algunos señalamientos que resaltan el olvido de características definidas socialmente como femeninas, dado el ambiente militar de la organización.

Frente a la primera subcategoría, relativa a los nuevos aprendizajes, las mujeres excombatientes mencionaron:

P4: uno de mujer aprende a ser fuerte, uno no se le doblega a cualquiera o cualquiera no lo doblega a uno.

P1: hay un régimen de igualdad, hombres y mujeres son iguales. En trabajo pesado es igual. Es bonito porque la mujer nunca fue discriminada, siempre fue muy ayudada.

P5: fue el choque asi grandísimo, pues como siempre hemos estado en esa cultura patriarcal $y$ siempre nos inculcaron a nosotras las niñas que nosotras éramos para cocinar, para hacer el aseo de la casa, y yo llegué allá y no, que todos haciamos lo mismo, que todo era por igual, yo llegué y me dijeron: "usted es libre de decidir sobre su persona, su sexualidad, sus cosas" (...) el respeto era tan grande; me sorprendi mucho, muchísimo, aunque sí, yo siempre he sido tímida y pues la primera vez que me mandaron a bañar yo no sabía si meterme al caño con todos o quedarme de última pero desde esa primera experiencia de respeto infinito, con los muchachos que estuvieron en esa época con nosotras...

Como se lee en el último relato, la mujer excombatiente resalta el respeto que se tenía por la mujer, esto desde su experiencia. Asimismo, se resalta cómo la organización le muestra a esta mujer otra faceta de ella misma, una que se aleja de 
aquello enseñado en su familia, lo cual se anclaba a la organización patriarcal.

Por otro lado, una de las entrevistadas resalta el aprendizaje de "ser guerrillera" el cual se define a partir de las formas de trato hacia los otros, independientemente de quien sea este otro:

P2: lo más importante que aprendi es cómo ser guerrillera, es el trato que uno tiene que darle a las otras personas, el respeto que uno tiene que tener ante las personas, sea lo que sea, así sea el peor enemigo de uno, entonces uno tiene que respetar mucho, valorarle la vida como ser humano, que porque uno está empuñando un arma, no, tampoco, no puede aprovecharse de eso.

Sin embargo, una de las mujeres excombatientes resalta las dificultades dentro de la organización desde la perspectiva femenina, las cuales parten de la negación de lo femenino, encontrando la imposibilidad de acceder a aquellos recursos que ratificaban su ser como mujeres. Así, los discursos alrededor de la igualdad de sexos rompen con el universo de significados de lo que es hombre y mujer, algo positivo en la medida en que posiciona a la mujer en un espacio social y de lucha; sin embargo, dicho discurso permite la disolución de las diferencias que son propias a cada uno de los sexos y que permiten identificarlos como tal. Estas últimas van más allá de las ideas sociales patriarcales asociadas al ser femenino: son límites que, al ser disueltos, afectan la subjetividad de la mujer y la igualan dentro de un contexto hipermasculinizado. De esta manera, la igualdad se constituye como un arma en contra de la propia manifestación libre de la mujer. Frente a lo anterior y tras el análisis de diferentes investigaciones con excombatientes de las FARC-EP, Mejía \& Anctil (2017), encuentran que:

Al basar la liberación femenina en el cumplimiento de tareas indiferenciadas, puede llegar a darse un convencimiento de la existencia de igualdad, pasando desapercibido el sustento guerrerista de los discursos que sostienen el conflicto armado, cuyo objetivo no es la igualdad, sino la uniformización de los cuerpos y la eliminación del o de la oponente (p. 110).

A continuación, se muestra uno de los testimonios de las mujeres entrevistadas, quien hace a alusión a la falta de aquello característico para una mujer:
P3: en ocasiones, hay veces que uno no tenía toallas, y le tocaba uno por ahí con un chirito y el periodo, cuando estaban las cosas buenas a uno le traen el shampoo, que la crema que una cosa y cuando no, jabón rey y ya, loción, paila (...) hay veces que uno no tenía moñitas y se hacía un moño con cualquier cosa para amarrarse el pelo, porque no había más (...) el día que uno se maquillaba le decían los muchachos, ¡Uy! salieron las brujas porque uno ¿cuándo se pintaba? y pues llegaba los diciembres $y$ todo pintoreteado uno y comenzaban a burlarse de uno, y que uno acostumbraba a vestir ancho (...) como mujer uno lo pierde, a uno no le importaba irse a bañar así normal con brasieritos, ropita interior normal, era normal uno irse a meter a un baño, ahí a un caño normal, también uno va perdiendo todo ese ambiente, uno mantiene relacionado con los hombres y eso pasa, uno como que pierde la vaina de ser mujer.

Claramente, como lo expresa la mujer entrevistada, el contexto de guerra limita y las cualidades asociadas a lo femenino son desplazadas por aquellas pertenecientes al guerrero masculino. Relacionado con lo anterior, Blair \& Londoño (2003) resaltan la ambigüedad a la cual se enfrentan las mujeres dentro de la organización, pues, socialmente, lo considerado como fuerte es valorado de manera positiva, situación que las obliga a reestructurar su propia identidad:

La guerra y su participación en ella como combatientes enfrenta a las mujeres a un gran desafío: la ambigüedad de una acción donde deben "masculinizarse" para hacer la guerra -lo que va desde vestir los "masculinos" uniformes militares, hasta hacer gala de la tenacidad y valentía cuando no de acciones francamente heroicas para el combate, como reto para ser aceptadas, reconocidas y visibilizadas, con altos costos para su identidad- o reivindicar su identidad de género a costa del desconocimiento y el rechazo (p. 113).

La complejidad que representa el escenario de guerra se manifiesta en este desafío de identidad, pero, así mismo, en la satisfacción del mismo para la manifestación de habilidades y posibilidades que veían restringidas por el hecho de ser mujeres: en concreto, la conciencia de libertad y respeto (Herrera \& Pertuz, 2015). En resumen, los relatos escuchados sintetizan y expresan las particulares experiencias de mujeres que vivieron de manera diferencial su paso por la guerrilla. Algunas mujeres, 
resaltando lo aprendido en su paso por la organización, relativo, principalmente, a la reconfiguración de su ser como mujer. Otras, recordando aquellas experiencias negativas asociadas a la pérdida de lo femenino en un escenario eminentemente construido por la masculinidad.

\section{Ser madre en la organización}

Uno de los temas más controversiales ha sido el ser madre dentro de la organización. Por ejemplo, Uribe (2016) menciona que de manera coercitiva las FARC vulneraron los derechos de las mujeres integrantes de la organización, con la finalidad de cumplir con sus objetivos. De manera específica señala la restricción al ejercicio en plenitud de sus derechos sexuales y reproductivos. Asimismo, Patiño \& Patiño (2012) ponen de manifiesto cómo el embarazo se convertía en una amenaza para la seguridad del grupo y el aborto se posicionaba como la estrategia de solución. Sin embargo, Barrera (2018) denuncia el uso del tema para la victimización de las mujeres combatientes, al restarles su poder de agencia.

Las mujeres entrevistadas dieron sus diferentes puntos de vista y contaron sus experiencias al respecto. De esta manera, emergieron dos subcategorías: una relacionada con el control del embarazo y la otra con la entrega de los menores cuando el embarazo se llevaba a término, en algunos casos a familiares y, en otros, a desconocidos.

Frente al control del embarazo, las mujeres excombatientes cuentan que existian fuertes controles, pues se le mencionaba a la mujer que ingresa que el contexto de la guerra no permitiría tener hijos en la organización. Al respecto:

P4: no, eso sí era delicado, porque aquí le exigian a uno mucho la planificación, la planificación era primordial por que no estaba permitido por la cuestión de la guerra, muchas veces porque si paría tocaba dejárselo por ahí a cualquiera que uno encontrara, tenga le doy mi hijo porque qué, era una mata y uno para ir con un operativo, hay veces que a uno le tocaba aguantar hambre, pasar mojado y un bebé de esos pues peor todavía, pues era complicado y que también uno se hacía daño fisicamente, mentalmente.

P1: sí había un tiempo que, si uno se descuidaba, por la cuestión de los operativos u otras cosas, había muchas mujeres que no los podian tener. Muchas estaban de acuerdo que los botaran, daban una orden para que los botaran, porque no se veian las condiciones para que ese bebé se pudiera conducir, porque en ese orden no había la cantidad de tierra para darle lo que necesitaba ese bebé. Y uno era consciente de ello, desde la primera vez que pasas a la fila, te indican eso: "ino puede tener bebés! Porque las condiciones no se dan para eso. Somos una fuerza armada, no para producir niños. Es para defender a nuestro pueblo, nuestra comunidad"

P5: de todas maneras, uno cuando ingresa le hacen claridad sobre eso y uno mismo va adquiriendo esa conciencia, de que uno por ejemplo una organización irregular que éramos nosotros pues no se pueden tener hijos, además porque éramos militares y usted imaginese en un combate y uno con bebé, yo como guerrillera dentro de la organización nunca tuve problema por ese sentido, yo era consciente de que aquí no se puede tener hijos, yo dije algún día pues, si habrá una oportunidad, pues ya será otra cosa.

Sin embargo, existieron ocasiones donde se permitió concebir al bebé, el cual era entregado a familiares de la madre:

P4: jimm!, (risas) pues yo ingresé y a los cuatro meses quedé en embarazo, o sea, no, nunca me exigieron la planificación y cuando me la exigieron ya era demasiado tarde y pues a mí me daba sueño, náuseas, yo le cogí mucha rabia al arroz con pasta frita y entonces me decía "usted está embarazada" y yo decía que no, cuando yo le dije a la enfermera "tómeme una prueba de embarazo", me la tomaron y, cuando sale positiva , yo no sabía si gritar, reírme, llorar, jmm y yo una niña... delicado eso... yo la pensaba por eso... pero mira que afortunadamente que por ser tan niña el comandante me dijo "téngalo pero no vaya a montar problemas por ahi, usted sabe cómo es la vuelta" y yo le dije que sí y así fue como lo pude tener, en ese tiempo yo tenía mi familia, los llamé y ellos vinieron por el niño.

P2: pues yo tengo dos, pero esos son como si no fueran mios porque desde chiquitos fueron criados por otros.

P1: sí, es dificil, eso fue lo que me pasó; tener que entregarlos bebecitos y yo tener que aguantarme de mi propia sangre.

En los relatos se evidencia que el tema de la maternidad no era permitido dentro de la organización, pues se entendía que las condiciones de guerra no permitirían la crianza de un menor. Por esto, en la mayoría de los relatos, se lee la entrega 
de los hijos a familiares o desconocidos, siendo las mujeres conscientes de la situación desde el momento en el que ingresan a la organización.

\section{Posacuerdo: los miedos y el proyecto de vida}

Resalta Barrera (2018) el entendimiento de las mujeres excombatientes respecto a la paz: un entendimiento que trasciende de la paz como sinónimo de ausencia de conflicto, pues para la mujer, desde el escenario de combate la paz, esta se conceptualiza como transformación. Con esto, el conflicto se convierte en un motor para la movilización de la acción trasformadora. Bajo tal óptica emerge la última categoría de análisis, la cual recoge los testimonios de las mujeres excombatientes en clave del escenario de posacuerdo y los retos de construcción de paz. De esta manera, emergen tres subcategorías clave objeto de atención en el posacuerdo:

- Miedos: en esta subcategoría se agrupan las respuestas de las excombatientes referidas a la inseguridad proveniente ya sea de las acciones de grupos paramilitares o emergentes, así como del incumplimiento del gobierno frente a los acuerdos alcanzados y el rechazo de la ciudadanía.

- Proyecto de vida: si bien algunas mencionaron el deseo de establecerse en zonas rurales y ejercer labores agrícolas, se resalta en esta subcategoría las respuestas concernientes al futuro como voceras políticas y como madres, pues, frente al primero, se reconoce que dentro de la organización armada se aprendieron habilidades que deben ser aprovechadas para la construcción de paz; frente al segundo, las mujeres excombatientes desean generar espacios familiares para sus hijos en un ambiente de paz y cariño.

- Perspectivas de paz: dentro de esta subcategoría se recogen las menciones frente a la construcción de paz y el aporte de las mujeres excombatientes a esta.

Respecto a la subcategoría “miedos”, el tema dela seguridad es el principal obstáculo que enfrentan las mujeres excombatientes en este escenario de paz, pues, desde la firma del Acuerdo Final, se han presentado 71 excombatientes asesinados (Misión de Verificación de las Naciones Unidas en Colombia,
2018) y, en el periodo de 2010 a 2018, fueron asesinados 609 líderes sociales (El Espectador, 2018). Lo anterior representa importantes riesgos para la implementación del Acuerdo Final y la reinserción social de los y las excombatientes, así como para el ejercicio del liderazgo regional.

De esta manera, las entrevistadas señalan sus miedos frente a la existencia del paramilitarismo, la garantía de su seguridad, la de sus futuros hijos y las de sus familias:

P1: sí, más de uno sí pensamos, uno sí lo piensa, que corre el riesgo de sufrir alguna cosa, no del Estado, pero sí por parte de los paramilitares, porque esa es la causa más dañina que hay hoy en dia, que matan y matan, deben de acabar con el paramilitarismo.

Una de las excombatientes, recordando el genocidio de la Unión Patriótica, partido político resultante de los Acuerdos de la Uribe, sobre el cual recayó la acción genocida del paramilitarismo con patrocinio del Estado colombiano que dejó más de 1.500 víctimas fatales (Verdad abierta, 2016), señala:

P5: por ejemplo, por las muertes de los lideres sociales y que, aunque se dice que no son sistemáticas, empiezan a mostrar lo mismo que pasó con la Unión Patriótica pero quizá todos esos años de lucha y experiencia nos van a ayudar a ir abriendo camino por la vía política y este espacio donde todas las mujeres tenemos que asumir la misma tarea (...). Nos genera preocupación, digo nos genera porque es de los excombatientes, es que la muerte de los que estaban en los territorios de los lideres sociales desencadene una masacre como la que vivió la UP y no se nos permita nuestra participación política.

Otros de los miedos se relacionan con el cumplimiento del gobierno de los acuerdos de paz y de la actitud de la ciudadanía frente a su llegada a la sociedad, pues, como se ha encontrado en diferentes investigaciones, las mujeres excombatientes son recibidas como traidoras por abandonar a sus hijos y sus familias, se espera, asimismo, que en la civilidad jueguen los roles estereotipados diseñados por la sociedad- Esto es contrario al prestigio del excombatiente masculino (Romero, 1995; Theidon, 2009). Al respecto, mencionan Boutron \& Gómez (s.f.):

Las mujeres combatientes en efecto encarnan una doble transgresión: no solamente infringen la 
ley, sino que también rompen con los estereotipos tradicionales de género. En muchos casos se considera que, por haber sido incorporadas en un grupo armado, han sido promiscuas o víctimas de violencia sexual, lo cual ha representado en otros contextos un freno insuperable para organizarse en pareja, casarse y formar una familia. Adicionalmente, para las mujeres excombatientes regresar a la vida civil puede significar reencontrarse, a pesar de sus expectativas, con roles y tareas tradicionales asignadas a las mujeres. Esto es resultado no solo de los anhelos de sus familias, sino también de las orientaciones de las propias instituciones estatales encargadas de las políticas y programas de reintegración a la vida civil de las excombatientes. (p. 3).

Se reconoce que son múltiples los desafios de las mujeres excombatientes, los cuales se traducen tanto en aquellos propios de su pertenencia anterior al grupo armado, como en los relacionados con el hecho de ser mujeres. A pesar de esto, las mujeres entrevistadas construyen su nuevo proyecto de vida a partir de las vivencias recogidas durante su paso por la organización, manteniendo un espíritu político y soñando con la integración con las comunidades. La siguiente frase resume este propósito: "mis proyectos futuros es tener un pueblo adelante, una unión, una comunidad que se entienda para trabajar, todos nos entendamos. Ese es mi proyecto.” Además, menciona otra de las entrevistadas:

P5: yo a futuro sí me veo haciendo una labor social grandísima a través de una representación pública (...), pero eso requiere preparación, eso no es por azar, yo creo que uno tiene que ser muy responsable con ese tipo de propuestas porque no es solamente mi destino si no el de toda la gente que deposita su confianza y uno no puede ser inferior a esa responsabilidad, a mí sí me daría susto ser inferior a esos votos de confianza y pues para eso uno tiene que irse preparando(...), sí se pueden hacer las cosas y pues para allá me proyecto.

Asimismo, se plantean como proyecto brindar una familia a sus hijos, tanto aquellos que un día tuvieron que entregar como los que vienen en camino:

P3: para mi hija me gustaría que tuviera un futuro bonito en estudios, humildemente, humildemente, lo anhelaría, como nos criamos nosotros, o como nos hemos criado toda la vida, y pues como mi mamá me enseñó y que fuera revolucionaria me gustaría, hasta uno aprende mucho y pues me gustaría, me gustaría que viviera del estudio, que pudiera coger una carrera que ayudara al pais, algo que sea un futuro para ella y para los demás, eso me gustaría.

Asimismo, las mujeres excombatientes demuestran en sus relatos un gran compromiso por la paz en Colombia, sintiendo gran esperanza por el futuro del país y por la organización política derivada de los acuerdos. Lo anterior también es expresado por Sánchez - Blake (2012), quien señala que el $80 \%$ de desmovilizadas trabaja o ha trabajado por la paz desde el momento de su reinserción a la sociedad. De esta manera, se lee en uno de los relatos el gran compromiso por la lucha desde la palabra y el escenario político tanto por la paz como por la garantía de los derechos sociales:

P3: me siento feliz porque pues yo sé que nosotros estamos haciendo algo por los hombres, por los civiles; bueno, a nosotros nos niegan mucho los derechos viviendo en la población civil, porque nosotros vivimos en comunidad, todos con valores; mientras que en la civil el que tiene bien y el que no, no; por eso me siento bien; si cumplen al menos va a haber como esa igualdad para todos, me siento orgullosa.

P1: yo me siento tranquila, porque estamos en un proceso de paz (...) porque mucho pueblo se va unir a trabajar con nosotros. Contenta porque ya se va acabar el conflicto y ellos quieren lo mismo que nosotros, que se acabe el conflicto para que no exista más guerra, ni sangre derramada o más madres sin hijos, sufriendo. Por eso yo me siento orgullosa y para adelante. Y pues las madrecitas, así como dice el dicho "ya sea de allá o de acá ellas están sufriendo" y entre nosotros, hijos de un pueblo, entre nosotros matándonos en son de nada, ni ganando sueldo de allá ni acá. Pero acá uno es consciente de que no estas ganando nada, solo defendiendo al pueblo, porque el grande capitalismo se lo está comiendo. Que se acabe eso y que todos seamos unidos. Ojalá que no vaya a pasar nada.

De esta manera, las mujeres entrevistas rechazan la idea de volver a las armas y señalan que, con el Acuerdo alcanzado, han ganado la oportunidad de defender sus ideas desde el escenario político:

P5: hemos avanzado bastante como para retroceder, desde que se formaron las FARC, el objetivo era resolver el conflicto por vía pacífica, eso no se nos 
ocurrió ahorita, y yo pienso que ahorita el reto más grande es mantener lo que tenemos hasta el momento (...) yo pienso que tenemos ahorita el arma de la palabra y que vamos a lograr grandes cosas, yo pienso que todos hemos sufrido las consecuencias de la guerra (...)"

P2: yo no me veo nuevamente cargando un fusil $y$ un equipo porque nosotros tenemos que llegar al corazón de las masas, a la gente del común y la violencia ha dejado muchísimas víctimas.

\section{Conclusiones}

Esta investigación pretendió responder a cuestionamientos como ¿quiénes son las mujeres excombatientes?, ¿qué necesidades tienen en este escenario de construcción de paz?, ¿cuáles son sus principales retos? Lo anterior se logró mediante el uso de información institucional y el acercamiento a los relatos de vida de cinco mujeres excombatientes. Dado esto, se presentan a continuación algunas conclusiones del proceso investigativo.

Es importante reconocer que la cantidad de excombatientes de las FARC-EP, hombres y mujeres, no es despreciable: para el año 2018, 19.539 personas se encontraban en proceso en la ARN, lo anterior sin considerar el número de excombatientes de otros grupos armados ilegales. Esto implica que el gobierno nacional no puede ignorar su responsabilidad en la implementación de los lineamientos de política que hasta la fecha se han creado, especialmente, aquellos que se consignan como parte del Acuerdo Final (Huertas, 2016).

Los hombres y mujeres excombatientes son más que excombatientes, es decir, son personas con deseos, metas y sentimientos. La violencia ha permitido que al combatiente (ahora excombatiente) se le desplace a una esfera alterna, a la cual los civiles no pertenecen, lo que genera una sensación de extrañeza y rareza que permite la exclusión y el rechazo. Sin embargo, son hombres y mujeres con familias, con hijos o con deseos de estructurar lazos familiares y sociales en un momento considerado de paz. Esto se demuestra con las altas cifras aportadas por la ARN de mujeres con pareja y con hijos, además de los relatos de vida de las mujeres entrevistadas, cuatro de ellas en estado de embarazo. Reconocer esto implica que las políticas que deben ser generadas o las ya generadas para los excombatientes y su reincorporación a la vida civil deben trascender de la noción de la no reincidencia a la noción de la humanidad, la cual permitiría recuperar al excombatiente de la dimensión de la rareza.

Facilitar lo anterior pasa por reconocer las particularidades de vida y motivaciones que cada hombre y mujer tuvo para su vinculación al grupo armado. Teniendo en cuenta los resultados de esta investigación, se encuentra que, para las mujeres en particular, su familia de infancia se caracterizó por brindar escenarios de socialización tradicionales, donde esta era concebida como parte del escenario privado en contraposición del papel que se le restringía en lo público. Dichos escenarios son típicos en Colombia, especialmente en las zonas rurales -lugares de procedencia de la gran masa de excombatientes hombres y mujeres de las FARCEP- en los cuales la mujer es delegada al ámbito del trabajo dentro del hogar, restringiéndosele el manejo de asuntos económicos ligados a la producción campesina (Ballara \& Parada, 2009). Esta situación ha permitido la consolidación de roles para hombres y mujeres, en los cuales los primeros ostentan una posición de poder y, las segundas, una posición de dependencia: esta situación legitima la violencia contra la mujer (Huertas, 2017), pues, como lo señala González (1995), la mujer tenía como campo de acción la jefatura del hogar en lo relacionado con las tareas domésticas y los hijos, mientras que el hombre desplegaba sus cualidades en el mundo del trabajo y de la política. Sin embargo, esto se rompe con la incursión de aquella mujer campesina en las guerrillas, pues, ya sea por los ideales de la organización o por la influencia social, ingresa en un escenario en el cual se posiciona como un actor social importante (Jiménez, 2014).

Por otra parte, la vinculación de las mujeres en las guerrillas también evidencia el abandono estatal de las comunidades rurales de las que ellas provenían, pues, tal como se puede leer en los resultados de la investigación, la guerrilla hacía presencia permanente en los lugares en los que ellas habitaban o frecuentaban, constituyéndose en la figura de autoridad ante la ausencia de las instituciones del Estado. El CNMH (2014) señala la trayectoria de las FARC y su vinculación con las comunidades desde 1949. Así, en un primer momento, esta organización se fundamenta en las ideas politicas del Partido Comunista Colombiano, defendiendo los derechos del campesinado, constituyéndose, de esta manera, como una guerrilla de origen campesino. En un segundo momento, las FARC, como organización guerrillera, llegan a 
ocupar los territorios periféricos abandonados por el Estado colombiano, obteniendo un gran apoyo social en ellos: esto les sirve para fortalecerse política y militarmente. Es en este periodo en el que se ubican muchos de los y las combatientes, pues en sus territorios existía la presencia naturalizada de la guerrilla como aquella institución reguladora y defensora de sus intereses. Igualmente, la incursión del narcotráfico en la guerrilla permitió la obtención de apoyo comunitario, precisamente, de aquellos que subsistian mediante el cultivo de coca. Posteriormente, tras el reconocimiento de la lucha armada como política, se abren paso las negociaciones con diferentes gobiernos y la inclusión de los líderes guerrilleros en la política: se tuvieron situaciones de retroceso ante el genocidio político de la Unión patriótica. Una conclusión lógica de esto parte de la falta de participación activa del Estado en las comunidades, pues su ausencia precipitó el fortalecimiento humano e ideológico del grupo armado. Sin embargo, luego de la salida de los combatientes de las FARC de los territorios, el Estado colombiano no ha ejercido el control requerido, lo cual ha generado la ocupación de nuevos actores. De esta manera, señala la Fundación Paz y Reconciliación (2018) que, de los 242 municipios donde operaban las FARC, hay un grupo de 78 municipalidades con problemas graves de seguridad, en los que se ha presentado la ocupación criminal de disidencias de las FARC, la expansión ELN y/o la expansión de grupos armados organizados (GAO).

Reconocer que los ideales defendidos por la organización fueron una motivación de ingreso para algunas mujeres implica la relevancia de la voz política de la mujer excombatiente y la necesidad de su legitimación dentro de los escenarios de decisión del país. Asimismo, las dinámicas llevadas a cabo dentro del grupo armado permitieron el empoderamiento de las mujeres, situación que debe ser potencializada y reconocida. La no generación de estrategias de potencialización de los roles de equidad puede derivar en la transformación de la conciencia de género por parte de las mujeres excombatientes, lo que generaría volver al rol tradicional femenino reforzado por las concepciones sociales de los ciudadanos. Al respecto, señalan Abogados Sin Fronteras \& Corporación Humanas (2018):

Sobre la última, recae un estereotipo como trasgresora de normas sociales y conductas esperadas de una mujer. Por lo mismo, la reintegración de las mujeres debe pensarse desde esta realidad y los estereotipos socioculturales que permean las instituciones del Estado y que pueden traducirse en impedimentos para la garantía de sus derechos (p. 12).

La mujer excombatiente entrevistada decide ingresar a la organización: no fue reclutada forzosamente. Esto implica trascender de la noción victimizante que siempre se le ha adjudicado a la mujer en Colombia, sujetándola al proteccionismo del Estado y limitándola en la vida pública, Asimismo, se deben impulsar acciones diferenciales tanto para las mujeres que ingresaron de manera forzada a la organización como para las que no, reconociendo el impacto diferencial en cada una de ellas, pues es importante no desconocer la existencia de víctimas. Sin embargo, precisamente, su reconocimiento parte del poder de su voz y de la participación en los diferentes procesos de juzgamiento a los responsables. Esto implica, además, el fortalecimiento del acceso a la justicia de las mujeres excombatientes, legitimando sus testimonios e historias de vida.

Un aspecto relevante encontrado en la investigación se relaciona con la edad temprana de ingreso al grupo armado y la permanencia extendida en este. Al respecto, diferentes investigaciones (Cuevas \& Castro, 2009; Palmou, s.f.) han evidenciado la existencia de consecuencias negativas de la vinculación temprana a un grupo de naturaleza violenta, señalando consecuencias psicológicas (depresión, ansiedad) como predictores de carreras criminales. Si bien la investigación no aborda estos aspectos en particular, se acoge la recomendación de Caicedo (2016) relativa a la "reorientación de los conocimientos que adquirieron para la guerra en conocimientos para preservar la vida, cuidar y construir" (p. 10). No obstante, el re direccionamiento de aprendizajes negativos, debe acompañarse de iniciativas de empleabilidad, siendo este un factor crítico para la reincidencia (García, 2015).

En relación con lo anterior, los datos de la ARN demuestran que la mayoría de los excombatientes se encuentran en el sector informal, lo cual no es positivo si lo que se pretende es que aquellos vivan dentro de los parámetros de la legalidad. Asimismo, en este punto, es importante resaltar los postulados consignados en el Acuerdo Final relativos al fortalecimiento del campo, pues, dada la vocación agrícola de los excombatientes de las FARC 
y los testimonios en los cuales es la vida rural la deseada, se deben recuperar dichos lineamientos para su implementación, permitiendo la configuración de empleos rurales para aquellos que deseen continuar allí. Esto debe hacerse generando una política agraria integral, que trascienda del abandono tradicional del Estado al campo colombiano. Sin embargo, es importante resaltar lo mencionado por la Corporación Humanas (Caicedo, 2016) relativo al desplazamiento de las mujeres de los ETCR por la no garantía de servicios básicos de salud, ni de condiciones de habitabilidad, así como por la falta de derechos sobre la tierra, lo cual impide la generación de proyectos, propiciando que estas abandonen los territorios en búsqueda de mejores oportunidades. Adicionalmente, la reintegración económica se encuentra limitada por los estereotipos sociales que persisten actualmente: por esto, la institucionalidad colombiana deberá atender las necesidades de las mujeres excombatientes mediante la generación de empleo rural y urbano, pero, sobre todo, generar estrategias para la reconfiguración de pensamientos que limitan las posibilidades de reintegración económica por parte de la mujer excombatiente (Abogados Sin Fronteras \& Corporación Humanas 2018).

Otro asunto importante encontrado en la investigación se refiere a la familia actual y a la maternidad de la mujer combatiente. Así, en los testimonios de las entrevistadas se hallan relatos relacionados con el fuerte control a la maternidad, bajo la justificación de las circunstancias de la guerra. Algunas investigaciones cuestionan dicha posición frente a los discursos de igualdad pregonados por el grupo guerrillero, señalando que la pérdida de individualidad de la mujer, en razón de los propósitos del grupo, permiten la invisibilización de ella como individuo. Así, aunque la igualdad entre sexos se cumple, la homogeneidad de las poblaciones vulnera las libertades de las mujeres (Mejía \& Anctil, 2017). Pero, más allá de esto, se debe reconocer la existencia de cientos de menores que nacen en el contexto de la confrontación y que son entregados a familias o desconocidos, así como aquellos que están naciendo y creciendo en los ETCR (Defensoría del Pueblo, 2017). Reconocer, entonces, que los excombatientes tienen familias implica la protección de los menores en los diferentes niveles, especialmente el de la discriminación. Asimismo, se deben generar estrategias para el acompañamiento de la reunificación familiar, reconociendo los impactos a nivel psicosocial de la separación, pues el Acuerdo de Paz ha permitido el reencuentro de cientos de mujeres excombatientes con sus hijos (Defensoría del Pueblo, 2017).

Otra de las conclusiones de esta investigación se relaciona con el tema de la seguridad. Algunas investigaciones han demostrado la importancia de la garantía de la seguridad de los y las excombatientes como garantía de la no reincorporación o reincidencia en actividades ilegales. Así, Nussio (2011) y Kaplan \& Nussio (2016), en investigaciones relacionadas con la reincidencia criminal de excombatientes de diferentes GAI, señalan que existen diferentes variables que influyen tanto en la reorganización de nuevas estructuras criminales, como en la permanencia de los excombatientes en un estilo de vida violento. Estas variables se agrupan en dos fuerzas o motivaciones: impulsoras y restrictivas.

Las fuerzas impulsoras se relacionan con: 1) condiciones económicas caracterizadas por su naturaleza desfavorable y que permiten la justificación de la iniciación de actos delincuenciales; 2) factores de seguridad relacionados a sentimientos de rivalidad frente a compañeros no desmovilizados o la existencia de GAI o estructuras criminales que hayan perseguido el perjuicio del grupo al cual el desmovilizado se encontraba vinculado, generando miedo, paranoia y estrategias de protección como la revinculación; 3) las oportunidades para el crimen (tales como la existencia de vínculos con ex compañeros o ex comandantes y habilidades específicas para el crimen). Por otro lado, las fuerzas restrictivas tienen en cuenta el nivel de control social. Así, la existencia de instituciones funcionales permite que el excombatiente permanezca en la legalidad, siendo importante la presencia y el significado de la familia para el individuo. Igualmente, la creación e implementación de estrategias de reincorporación adecuadas contribuyen al propósito de una vida libre de violencia para las personas desmovilizadas.

Dado esto y los diferentes testimonios de las mujeres excombatientes, es urgente la toma de medidas para proteger a las personas que, en la actualidad, están construyendo su vida en la civilidad, brindándoles las condiciones de seguridad que les permitan llevar a término positivo este propósito.

No obstante, a pesar de estas inseguridades y miedos, la investigación muestra un gran compromiso por parte de las mujeres excombatientes 
con la paz y la materialización de sus ideas políticas en dicho escenario, dejando atrás la confrontación armada y preparándose para el ejercicio político y la reconstrucción de sus familias. Es, entonces, deber del Estado apropiarse de las obligaciones que con el Acuerdo Final adquirió, despojándose de toda mancha ideológica que impida la construcción de la paz (Ruiz, 2019), reconociendo el potencial rol de las mujeres que, tras su paso por la confrontación, cambian radicalmente sus vidas y pensamientos, y obtienen aprendizajes que pueden ser replicados en la búsqueda de la construcción de un país equitativo y con justicia social.

\section{Referencias}

Abogados Sin Fronteras \& Corporación Humanas (2018). Situación de las mujeres rurales y mujeres ex combatientes en el marco del Acuerdo Final de Paz. Disponible en: https://www.asfcanada. ca/site/assets/files/7636/report colombia cedaw asfchumanas julio 2018 vf.pdf

Álvarez, J.L. \& Jurgenson, G. (2003). Cómo hacer investigación cualitativa: fundamentos y metodología. México, D. F.: Paidós.

ARN (2018). La reintegración en cifras. Disponible en: http://www.reintegracion.gov.co/es/lareintegracion/Paginas/cifras.aspx

Ballara, M. \& Parada, S. (2009). El empleo de las mujeres rurales: lo que dicen las cifras. FAO-CEPAL.

Barrera, A. (2018). Mujeres excombatientes y transformación de conflictos: paradojas de la construcción de la paz en la lucha armada. La manzana de la discordia, 13(2), 21-39.

Blair, E. \& Londoño, L. (2003). Experiencias de guerra desde la voz de las mujeres. Nómadas, 19, 106115. Disponible en: https://www.redalyc.org/ articulo.oa?id=105117940011

Boutron, C. \& Gómez, D. (s.f.).Para no pasar del fusil a la olla: retos de la reincorporación civil y política de las mujeres guerrilleras en Colombia. Disponible en: https://blogs.lse.ac.uk/ latamcaribbean/2017/03/08/para-no-pasar-del-fusil-a-la-olla-retos-de-la-reincorporacion-civil-y-politica-de-las-mujeres-guerrilleras-en-colombia/

Caicedo, L. (2016). Recomendaciones para un proceso de desarme, desmovilización y reintegración (DDR). Corporación Humanas - Centro Regional de Derechos Humanos y Justicia de Género. Disponible en: https://www.humanas.org. co/alfa/dat particular/ar/060716 Recomendaciones para un proceso de DDR - Humanas.pdf
CNMH (2014). Guerrilla y población civil. Trayectoria de las FARC 1949-2013. Bogotá: Imprenta Nacional.

Cuevas, M. \& Castro, L. (2009). Efectos emocionales y conductuales de la exposición a violencia en niños y adolescentes en Colombia. Behavioral Psychology, 17(2), 277-297.

Defensoría del Pueblo (2017). Informe Espacios Territoriales De Capacitación Y Reincorporación. Recuperado de: http://www.defensoria.gov.co/ public/pdf/Informe ETCR.pdf

El Espectador (24 de septiembre de 2018). Agresiones contra líderes sociales antes y después del acuerdo de paz. Disponible en: https:// colombia2020.elespectador.com/pais/agresiones-contra-lideres-sociales-antes-y-despues-del-acuerdo-de-paz

Elson, C. (2016). Testimonio in a post-revolutionary era: the writings of female ex-combatants. En: Women's writing in Colombia: An alternative history (pp. 143-184). New York: Palgrave Macmillan.

Fundación Paz \& Reconciliación (2018). Cómo va la paz. Disponible en: https://pares.com.co/ wp-content/uploads/2018/06/INFORME-FINAL-2018-ilovepdf-compressed.pdf

Galvis, M. (2009). Situación en Colombia de la violencia sexual contra las mujeres. Corporación Humanas, Centro Regional de Derechos Humanos y Justicia de Género

García, A. (2015). El acceso al empleo para población en proceso de reintegración, ex AUC: Una estrategia para la eliminación de obstáculos para la paz (tesis de maestría). Universidad Nacional de Colombia. Disponible en: http://bdigital. unal.edu.co/49813/1/andreamilenagarciahernandez.2015.pdf

GMH (2013). ¡BASTA YA!: Colombia: Memorias de guerra y dignidad. Bogotá: Imprenta Nacional.

González, Y. (1995). Movimiento de mujeres en los años 60 y 70 En: Velásquez, M. (Comp.), Las mujeres en la historia de Colombia. (pp. 258-278). Bogotá: Consejería Presidencial Para La Política Social, Presidencia de la República de Colombia.

Gutiérrez, F. \& Carranza, F. (2017). Organizing women for combat: The experience of the FARC in the Colombian war. Journal of Agrarian Change, 17, 770-778.

Herrera, M. \& Pertuz, C. (2015). Narrativas femeninas del conflicto armado y la violencia política en Colombia: contar para rehacerse. Revista de Estudios Sociales, 53, 150-162.

Huertas, O. (Ed.) (2016). Acuerdo final para la terminación del conflicto y la construcción de una paz estable y duradera. Bogotá: Editorial Ibáñez. 
Huertas, O. (Ed.) (2017). Femicidio y educación. Aproximaciones y construcción del discurso desde la práctica social. Bogotá: Universidad Nacional de Colombia.

Huertas, O., Ruiz, A. L. \& Botia, N. (2018). De mujer combatiente a mujer constructora de paz. Inclusión de la voz femenina en el escenario del posacuerdo. Ratio Juris, 12(25), 43-67

Ibarra, E. (2008). Guerrilleras y activistas por la paz en Colombia: incursión política y rupturas identitarias. Pensamiento Psicológico, 4(11), 65-84.

Jiménez, C. (2014). Las mujeres y la guerrilla: ¿un espacio para las políticas de género? Revista Iberoamericana de Filosofía, Política y Humanidades, 16(32), 383-397.

Kaplan, O. \& Nussio, E. (2016). Explaining recidivism of ex-combatants in Colombia. Journal of Conflict Resolutions, 1-30.

Lesmes, L. (2016). Historias de mujeres excombatientes en estado de reclusión. Tensiones socio-jurídicas en torno a la ley de justicia y paz. Disponible en: http://repository.urosario.edu.co/ handle/10336/12157?show=full

Mejía, Y. \& Anctil, P. (2017). Corporalidades y subjetividades sexuales: el caso de las mujeres excombatientes de las guerrillas colombianas. Revista de Trabajo Social e Intervención Social, 23, 97-122.

Misión de Verificación de las Naciones Unidas en Colombia (2018). Informe del secretario general. Disponible en: https://colombia.unmissions.org/ sites/default/files/n1829784.pdf

Navas, C. \& Penagos, J. (s.f.). Violencia sexual en el conflicto armado, su precio más barato que las balas, pero su valor una huella brutal e indeleble. Universidad Militar Nueva Granada. Disponible en: https://studylib.es/doc/8714766/art\%C3\%ADculo-violencia-sexual-contra-la-mujer-en-el

Nussio, E. (2011). Understanding Excombatants. Central themes in the lives of former paramilitaries in Colombia (tesis de doctorado). University of St. Gallen, Brusio (Graubunden), Suiza.

OPC (2015). Cifras: mujeres de organizaciones armadas ilegales en Colombia: acercamiento cuantitativo. Bogotá: Universidad Nacional de Colombia, USAID, OIM.

OPC (2016). Retos de las mujeres combatientes en el fin del conflicto. Bogotá: Universidad Nacional de Colombia.
Palmou, A. (s.f.). Carrera delictiva, criminología del desarrollo vital. Revista Pensamiento Penal. Disponible en: www.pensamientopenal.com.ar/system/files/2015/07/doctrina41536.pdf

Patiño, R. \& Patiño, C. (2012). Configuración de la identidad de desertores de la guerrilla colombiana. Psicología \& Sociedad, 24(3), 517-526.

Pizarro, E. (1991). Las FARC. De la autodefensa a la combinación de todas las formas de lucha. Bogotá: Tercer Mundo Editores.

Romero, I. (1995). La reinserción de la mujer ex-combatiente: Un legado de guerra. Realidad: Revista de Ciencias Sociales y Humanidades, 44, 369383. Disponible en: https://doi.org/10.5377/ realidad.v0i44.5203

Ruiz, A. L. (2019). Implementación del enfoque de género en el Acuerdo Final con las FARC-EP. Via Inveniendi et Iudicandi, 14(1), 91-128

Sánchez-Blake, E. (2012). De actores armadas a sujetos de paz: mujeres y reconciliación en el conflicto colombiano. La manzana de la discordia, 7(2), 7-14

Stanford. (s.f.). El papel de la mujer en la lucha sandinista. Disponible en: http://web.stanford.edu/ group/arts/nicaragua/discovery sp/women/

Theidon, K (2009). Reconstrucción de la masculinidad y reintegración de excombatientes en Colombia. Working papers, 5. FIP.

Universidad Nacional de Colombia. (2017). Caracterización comunidad FARC-EP: Resultados generales. Disponible en: https://www.elespectador. com/sites/default/files/pdffile/presentacion rueda de prensa julio 6 2017.pdf

Uribe, M. (2016). El estatus de los derechos sexuales y reproductivos de las mujeres en las FARC. Universidad San Francisco de Quito. Disponible en: http://repositorio.usfq.edu.ec/hand$\underline{\text { le } / 23000 / 5533}$

Valencia, O. \& Daza, M.F. (2010). Vinculación a grupos armados: un resultado del conflicto armado en Colombia. Perspectiva psicológica, 6(2), 429439.

Vanegas, J. (2017). “A mucho honor guerrillera!”: Un análisis sobre la vida de las mujeres guerrilleras en Colombia (tesis de maestría). Universidad Nacional de Colombia.

Verdad Abierta (15 de septiembre de 2016). Exterminio de la UP fue un genocidio político. Disponible en: https://verdadabierta.com/exterminio-de-la-up-si-fue-un-genocidio-politico/ 